Winterthurerstr. 190

$\mathrm{CH}-8057$ Zurich

http://www.zora.uzh.ch

Year: 2010

First aid kit for hypoxic survival: sensors and strategies

López-Barneo, J; Nurse, C A; Nilsson, G E; Buck, L T; Gassmann, M; Bogdanova, A $\mathrm{Yu}$

López-Barneo, J; Nurse, C A; Nilsson, G E; Buck, L T; Gassmann, M; Bogdanova, A Yu (2010). First aid kit for hypoxic survival: sensors and strategies. Physiological and Biochemical Zoology, 83(5):753-763.

Postprint available at:

http://www.zora.uzh.ch

Posted at the Zurich Open Repository and Archive, University of Zurich.

http://www.zora.uzh.ch

Originally published at:

Physiological and Biochemical Zoology 2010, 83(5):753-763. 


\title{
First aid kit for hypoxic survival: sensors and strategies
}

\begin{abstract}
Survival success under conditions of acute oxygen deprivation depends on efficiency of the central and peripheral chemoreception, optimization of oxygen extraction from the hypoxic environment and its delivery to the periphery, and adjustments of energy production and consumption. This article uses a comparative approach to assess the efficiency of adaptive strategies used by anoxia-tolerant and hypoxia-sensitive species to support survival during the first minutes to $1 \mathrm{~h}$ of oxygen deprivation. An aquatic environment is much more demanding in terms of diurnal and seasonal variations of the ambient oxygen availability from anoxia to hyperoxia than is an air environment. Therefore, fishes and aquatic turtles have developed a number of adaptive responses, which are lacking in most of the terrestrial mammals, to cope with these extreme conditions. These include efficient central and peripheral chemoreception, acute changes in respiratory rate and amplitude, and acute increase of the gas-exchange interface. A special set of adaptive mechanisms are engaged in reduction of the energy expenditure of the major oxygen-consuming organs: the brain and the heart. Both reduction of ATP consumption and a switch to alterative energy sources contribute to the maintenance of ATP and ion balance in hypoxia-tolerant animals. Hypoxia and hyperoxia are conditions favoring development of oxidative stress. Efficient protection from oxidation in anoxia-tolerant species includes reduction in the glutamate levels in the brain, stabilization of the mitochondrial function, and maintenance of nitric oxide production under conditions of oxygen deprivation. We give an overview of the current state of knowledge on some selected molecular and cellular acute adaptive mechanisms. These include the mechanisms of chemoreception in adult and neonatal mammals and in fishes, acute metabolic adaptive responses in the brain, and the role of nitrite in the preservation of heart function under hypoxic conditions.
\end{abstract}




\section{First Aid Kit for Hypoxic Survival: Sensors and Strategies ${ }^{\star}$}

\section{J. López-Barneo \\ C. A. Nurse ${ }^{2}$ \\ G. E. Nilsson ${ }^{3}$ \\ L. T. Buck ${ }^{4}$ \\ M. Gassmann ${ }^{5}$}

A. Yu. Bogdanova ${ }^{5, \dagger}$

${ }^{1}$ Laboratorio de Investigaciones Biomédicas, Hospital Universitario Virgen del Rocío, Centro Investigación Biomédica en Red para Enfermedades Neurodegenerativas (CIBERNED), Universidad de Sevilla, Sevilla, Spain; ${ }^{2}$ Department of Biology, McMaster University, Hamilton, Ontario, Canada; ${ }^{3}$ Physiology Programme, Department of Molecular Biosciences, University of Oslo, Oslo, Norway; ${ }^{4}$ Department of Cellular and Systems Biology, University of Toronto, Ontario, Canada; ${ }^{5}$ Institute of Veterinary Physiology, Zurich Center for Integrative Human Physiology, University of Zurich, Winterthurerstrasse 260, CH-8057 Zurich, Switzerland

Accepted 1/31/2010; Electronically Published 6/25/2010

\section{ABSTRACT}

Survival success under conditions of acute oxygen deprivation depends on efficiency of the central and peripheral chemoreception, optimization of oxygen extraction from the hypoxic environment and its delivery to the periphery, and adjustments of energy production and consumption. This article uses a comparative approach to assess the efficiency of adaptive strategies used by anoxia-tolerant and hypoxia-sensitive species to support survival during the first minutes to $1 \mathrm{~h}$ of oxygen deprivation. An aquatic environment is much more demanding in terms of diurnal and seasonal variations of the ambient oxygen availability from anoxia to hyperoxia than is an air environment. Therefore, fishes and aquatic turtles have developed a number of adaptive responses, which are lacking in most of the terrestrial mammals, to cope with these extreme conditions. These include efficient central and peripheral chemoreception, acute changes in respiratory rate and amplitude, and acute increase of the gas-exchange interface. A special set of adaptive mechanisms are engaged in reduction of the energy

\footnotetext{
* This article was prepared as an overview of a symposium at "Molecules to Migration: Pressures of Life," the Fourth International Conference in Africa for Comparative Physiology and Biochemistry, Maasai Mara National Reserve, Kenya, 2008.

${ }^{\dagger}$ Corresponding author; e-mail: annab@access.uzh.ch.
}

Physiological and Biochemical Zoology 83(5):753-763. 2010. (C) 2010 by The University of Chicago. All rights reserved. 1522-2152/2010/8305-9036\$15.00 DOI: $10.1086 / 651584$ expenditure of the major oxygen-consuming organs: the brain and the heart. Both reduction of ATP consumption and a switch to alterative energy sources contribute to the maintenance of ATP and ion balance in hypoxia-tolerant animals. Hypoxia and hyperoxia are conditions favoring development of oxidative stress. Efficient protection from oxidation in anoxia-tolerant species includes reduction in the glutamate levels in the brain, stabilization of the mitochondrial function, and maintenance of nitric oxide production under conditions of oxygen deprivation. We give an overview of the current state of knowledge on some selected molecular and cellular acute adaptive mechanisms. These include the mechanisms of chemoreception in adult and neonatal mammals and in fishes, acute metabolic adaptive responses in the brain, and the role of nitrite in the preservation of heart function under hypoxic conditions.

\section{$\mathrm{O}_{2}$ Sensing in Adulthood: Carotid Body}

The carotid body (CB), a small, neural crest-derived, paired organ located at the carotid bifurcation, is the principal arterial chemoreceptor in adult animals and humans. It is also a major component of the homeostatic acute $\mathrm{O}_{2}$-sensing system that activates the brain stem respiratory center to produce hyperventilation during hypoxemia (e.g., in high-altitude residents or in patients with chronic obstructive pulmonary diseases; López-Barneo et al. 2001; Weir et al. 2005). The CB parenchyma is organized in glomeruli, clusters of cells in close contact with a profuse network of capillaries and afferent sensory fibers joining the glossopharyngeal nerve. The most abundant cell types in the CB glomeruli are the neuronlike glomus or Type I cells, which are enveloped by processes of glialike, sustentacular Type II cells. Glomus cells are physiologically complex, as they express a broad variety of voltage- and ligand-gated ion channels as well as transient receptor potential and background $\mathrm{K}^{+}$channels. They contain secretory vesicles packed with neurotransmitters, notably ATP, dopamine, and acetylcholine (ACh). Because of the presence of voltage-gated membrane channels, glomus cells are electrically excitable and can repetitively generate action potentials. This property is particularly evident in rabbit glomus cells, which have relatively large voltage-dependent $\mathrm{Na}^{+}$currents. Glomus cell membrane depolarization induces a reversible neurosecretory response, dependent on extracellular $\mathrm{Ca}^{2+}$ influx, that can be easily monitored by amperometry (López-Barneo et al. 2001). Thus, glomus cells behave as presynaptic-like elements that establish contact with the postsynaptic sensory nerve fibers. About $15 \%-20 \%$ of the cells in the CB parenchyma are Type II cells, which while in vivo exhibit long processes surrounding Type I cells. Classically, Type II cells, which are nonexcitable and lack most of the 
voltage-gated channels characteristic of Type I cells, have been considered to belong to the peripheral glia with a supportive role. However, recent experimental data have strongly suggested that Type II cells (or a subset of them) are indeed dormant stem cells that in response to physiologic hypoxia, can proliferate and differentiate into new glomus cells (Pardal et al. 2007). Type II cells are at least in part responsible for carotid-body hypertrophy on exposure to chronic hypoxia.

Glomus cells are polymodal arterial chemoreceptors, although it is the sensitivity to acute changes in $\mathrm{O}_{2}$ tension that makes them essential for the classical adaptive hyperventilatory reflex in response to hypoxemia (López-Barneo et al. 2008). Glomus cells contain several classes of $\mathrm{O}_{2}$-sensitive $\mathrm{K}^{+}$channels whose open probability decreases during hypoxia (López-Barneo et al. 2001). Inhibition of the $\mathrm{K}^{+}$channels leads to glomuscell-membrane depolarization and an increase in the firing frequency of the cells, thus resulting in $\mathrm{Ca}^{2+}$ channel opening, transmembrane $\mathrm{Ca}^{2+}$ influx, and transmitter release. ATP, and possibly ACh, seem to be the transmitters that activate the afferent sensory fibers, whereas dopamine may have a predominantly inhibitory autocrine role (Zhang et al. 2000; LópezBarneo et al. 2001, 2008). Similar to the carotid-body glomus cells, other neurosecretory or contractile cells acutely responding to hypoxia (neonatal adrenomedullary chromaffin cells, cells in the neuroepithelial bodies of the lung, PC12 cells, or pulmonary arterial myocytes) also contain $\mathrm{O}_{2}$-sensitive $\mathrm{K}^{+}$ channels (López-Barneo et al. 2001; Weir et al. 2005; Nurse et al. 2006). Mechanisms of detection of the changes in oxygen levels are highly tissue and species specific. Among the final targets are several classes of $\mathrm{O}_{2}$-sensitive $\mathrm{K}^{+}$channels regulated by hypoxia in neurosecretory cells (i.e., glomus and adrenal chromaffin cells; López-Barneo et al. 2001). The mechanism of interaction of $\mathrm{O}_{2}$ with the channels is unknown. Oxygen could directly modulate channel function by direct allosteric interaction with the channel macromolecule; however, most researchers believe that ion channel modulation by oxygen is indirect and might involve some mediators, specifically reactive oxygen species (ROS; see Weir et al. 2005; López-Barneo et al. 2008).

\section{$\mathrm{O}_{2}$ Sensing in Neonates: Adrenomedullary Chromaffin Cells}

The carotid body glomus cells and adrenomedullary chromaffin cells derived from the sympathoadrenal sublineage of the neural crest; however, their functions as $\mathrm{O}_{2}$ sensors have a different developmental profile. Glomus cells in newborn rats are relatively insensitive to hypoxia; they gradually acquire adultlike hypoxic sensitivity by the first few weeks of postnatal life. In contrast, adrenal chromaffin cells are exquisitely sensitive to hypoxia in the perinatal period, and this sensitivity is lost during postnatal development, becoming largely absent in the rat by about the second week of postnatal life (Slotkin and Seidler 1988). Indeed, in adrenal chromaffin cells, the presence of this $\mathrm{O}_{2}$-sensing mechanism is critical for the neonate to survive hypoxic stress, for example, during asphyxia associated with the birthing process.
This adaptive mechanism initiates a critical catecholamine surge that aids in the preparation of the lungs for air breathing and in the regulation of cardiac function. In the lungs, this hypoxiaevoked catecholamine release aids in surfactant production and in the transformation in the lung from a fluid-secreting to a fluid-absorbing epithelium. Thus, neonatal adrenal chromaffin cells in several species, including humans, release catecholamine during hypoxic stress. Interestingly, the postnatal loss of this hypoxia-sensing mechanism occurs in parallel with the acquisition of a mature sympathetic cholinergic innervation via the splanchnic nerve (Slotkin and Seidler 1988). By this time, carotidbody hypoxic sensitivity is mature and can thus protect the animal against hypoxic stress. Similar to glomus cells, hypoxia sensing in adrenal chromaffin cells is mediated by inhibition of several $\mathrm{K}^{+}$channels, leading to and/or enhancing membrane depolarization, voltage-gated $\mathrm{Ca}^{2+}$ entry, and catecholamine secretion. In both cell types, inhibition of large conductance $\mathrm{Ca}^{2+}$-dependent $\mathrm{K}^{+}$channels appears to contribute to hypoxic sensitivity. In neonatal adrenal chromaffin cells, several lines of evidence suggest that the proximal mitochondrial electron transport chain is involved in the $\mathrm{O}_{2}$-sensing pathway as rotenone, a complex I blocker, mimics and occludes the effects of hypoxia in these cells (Thompson et al. 2007). This contrasts with the extramitochondrial rotenone-sensitive site, which is suggested to be involved in $\mathrm{O}_{2}$-sensing in glomus cells (López-Barneo et al. 2008). The coupling mechanism between the $\mathrm{O}_{2}$ sensor and $\mathrm{K}^{+}$channel inhibition is still unclear in adrenal chromaffin cells but appears to involve a decrease in mitochondrial ROS production. In exploring potential mechanisms that might lead to the postnatal loss of $\mathrm{O}_{2}$ sensitivity, it was hypothesized that activation of nicotinic ACh receptors (nAChR) on chromaffin cells, as would occur during maturation of functional cholinergic innervation, might be a contributing factor. Consistent with this notion, activation of nicotinic AChR in utero via maternal administration of chronic nicotine (1 mg/kg body weight/d) led to a selective loss of hypoxic sensitivity in adrenal chromaffin cells of affected neonates, whereas saline-injected controls had normal sensitivity. A similar loss of hypoxic sensitivity could be reproduced in culture by exposing dissociated neonatal rat adrenal chromaffin cells to chronic nicotine base $(50 \mu \mathrm{M})$ for $\sim 7 \mathrm{~d}$ in vitro; untreated control cells retained normal hypoxic sensitivity over a similar incubation period (Buttigieg et al. 2008). The effect of nicotine was abolished when cultures were coincubated with nAChR blockers such as mecamylamine, indicating a requirement for $\mathrm{nAChR}$ activation. The signaling mechanisms underlying this loss of $\mathrm{O}_{2}$ sensing are currently being explored and appear to involve regulation of $\mathrm{K}^{+}$channels that participate downstream in the transduction cascade rather than in more upstream sites such as the $\mathrm{Po}_{2}$ sensor itself. These data strongly suggest that activation of nicotinic AChR may contribute to the regulation of $\mathrm{O}_{2}$ sensitivity in adrenal chromaffin cells and provide a link between maternal exposure to cigarette smoke and loss of hypoxia tolerance, leading to neonatal morbidity. 


\section{$\mathrm{O}_{2}$ Sensing in Fish Gills: Neuroepithelial Cells}

Air-breathing tetrapods evolved from fish that did not have carotid chemoreceptors for the obvious reason that they lack true carotid arteries. In fish, the gills appear to be the key site for oxygen sensing, and while air-breathing vertebrates mainly regulate their ventilation by sensing $\mathrm{PCO}_{2}$, fishes primarily react to the $\mathrm{PO}_{2}$ of their blood and ambient water (Dejours 1975; Maxime et al. 1995). Although it has been apparent for a long time that the sites of $\mathrm{O}_{2}$ sensing are located within the gills of fishes (Perry and Gilmour 2002), it was not until recently that progress was been made in the identification and characterization of the cells involved. It was long suspected that the neuroendocrine cells in the gills described by Dunel-Erb et al. (1982) were responsible for signaling oxygen levels to the brain, but the ability of these cells to sense oxygen was verified only recently in studies of zebrafish (Danio rerio; Jonz et al. 2004; Jonz and Nurse 2006) and, subsequently, of channel catfish (Ictalurus punctatus; Burleson et al. 2006). The neuroendocrine cells were shown by Sundin et al. (1998) to contain serotonin (see also Coolidge et al. 2008), and they appear to occur on all four gill arches (Milsom and Burleson 2007). It is a tempting thought that they are homologous to the cells sensing oxygen in the $\mathrm{CB}$, because the carotid arteries are thought to be derived from the arteries of the third gill arch and may operate in a similar manner (Milsom and Burleson 2007).

\section{Facilitated Oxygen Extraction from Hypoxic Environment}

In addition to effective $\mathrm{O}_{2}$ sensors, fishes have developed an efficient mechanism to facilitate oxygen extraction from a hypoxic environment. The fish gill has been found to respond morphologically to changes in the ambient oxygen level. This was first seen in crucian carp (Carassius carassius), which were found to gain a 7.5-fold larger respiratory surface area in their gills when exposed to a few days of hypoxia (Fig. 1; Sollid et al. 2003). The transformation involved the apoptotic death of a cell mass (the interlamellar cell mass [ILCM]) that in normoxia is filling up the space between the gill lamellae (the site for gas exchange in fish gills). The induction of apoptosis in the ILCM also coincided with reduced mitosis. A similar mechanism has subsequently been found in other fishes, and it is likely that this response is induced by direct $\mathrm{O}_{2}$ sensing of the ILCM cells because the ILCM is unlikely to be innervated (Sollid and Nilsson 2006; Nilsson 2007). Subsequent studies showed that the ILCM is also reduced by high temperatures (Sollid et al. 2005) and that hypoxia-inducible factor 1 (HIF-1), which controls hypoxia-induced gene expression in animals including fishes (Nikinmaa and Rees 2005), is probably not involved in the reduction of the ILCM because temperature and hypoxia have opposing effects on HIF-1 levels in gills (Rissanen et al. 2006; Sollid et al. 2006).

Thus, in fish gills, at least two fundamentally different mechanisms for $\mathrm{O}_{2}$ sensing appear to be in operation. The first mechanism involves specialized neuroendocrine cells communicating ambient and blood oxygen levels to the brain, initiating short-term circulatory and ventilatory changes; the sec-

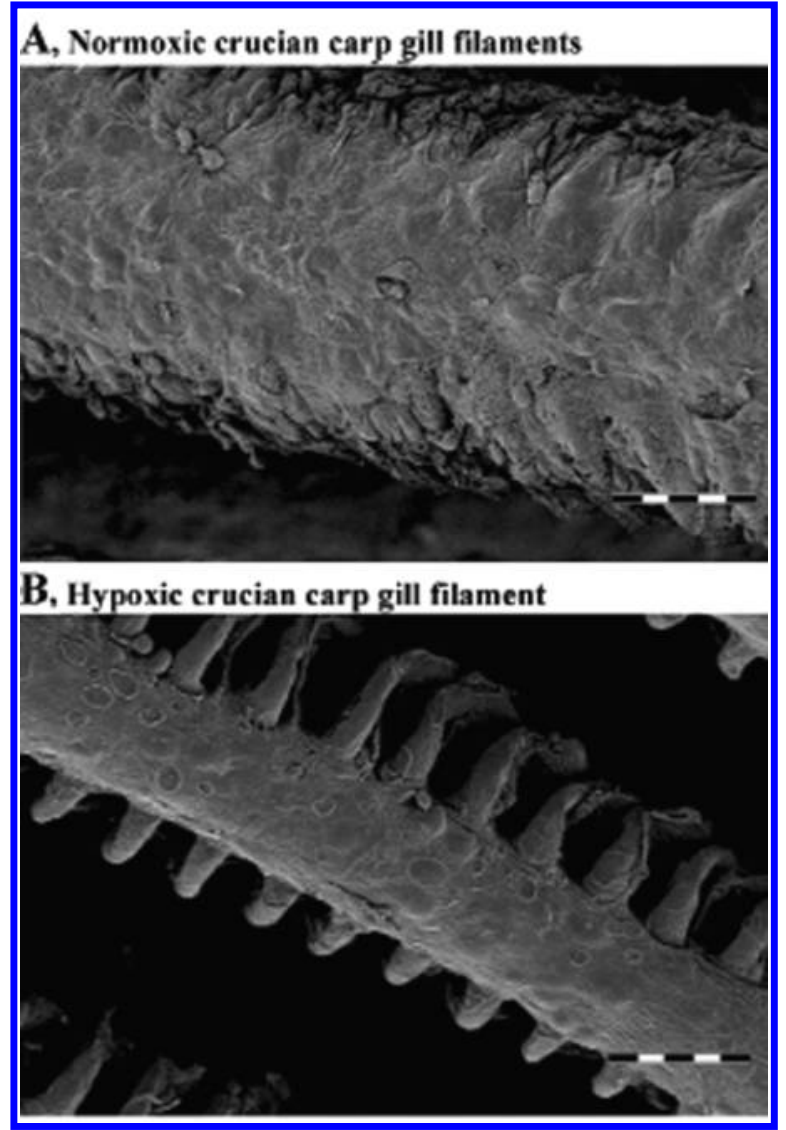

Figure 1. Hypoxia-induced remodeling of crucian carp gills in scanning electron micrographs show gill filaments from crucian carp kept in normoxic water $(A)$ and in hypoxic water $(B)$, both at $8^{\circ} \mathrm{C}$. Scale bars $=50 \mu \mathrm{m}$. From Sollid et al. (2003).

ond involves cells that regulate their own life and death, probably in direct response to oxygen or some related metabolic signal, thereby changing the respiratory surface area of the fish over a period of days. Both mechanisms will have a strong influence on the oxygenation status of the whole organism. Along with classical chemoreception occurring in neonatal adrenomedullary chromaffin cells and adult $\mathrm{CB}$, various organs in the body-including the lungs, blood vessels and circulating blood cells, brain, heart, and liver-are capable of autonomous $\mathrm{O}_{2}$ sensing. These peripheral sensors stabilize the cellular function under hypoxic conditions, preventing irreversible damage and adjusting oxygen demand to the changing oxygen supply. Among those sensors are ubiquitous ones such as mitochondria and tissue-specific ones such as various isoforms of nitric oxide synthases (NOSs), NAD(P)H (nicotinamide adenine dinucleotide [phosphate]) oxidases, and heme oxygenases (Ward 2008).

\section{Mitochondrial $\mathrm{O}_{2}$ Sensing}

Accumulating evidence suggests that mitochondria are actively involved in $\mathrm{O}_{2}$ sensing in the tissues mentioned above. These organelles play a pivotal role in cellular energy homeostasis and 
survival through apoptosis and necrosis, and they have been linked to protection from hypoxic or ischemic episodes through a preconditioning regimen in mammal heart and brain (Gross and Fryer 1999; Ardehali and O'Rourke 2005; Hanley and Daut 2005). They also play a role in regulating cellular calcium and ROS concentrations. With roles in so many important cellular processes, it is not unreasonable to imagine that mitochondria are involved in $\mathrm{O}_{2}$ sensing. After all, the terminal step of oxidative phosphorylation is reduction of oxygen to water by cytochrome oxidase, which is located in the inner mitochondrial membrane. The $K_{\mathrm{m}}$ of cytochrome oxidase for oxygen has been considered to be too low $(<1 \mu \mathrm{M})$ for mitochondria to function as $\mathrm{O}_{2}$ sensors. This is a "mammalocentric" point of view, reflecting the fact that mammals are unable to tolerate severe hypoxia or anoxia, although even in mammalians oxygen levels vary markedly between organs and even within single cells. In hypoxia- or anoxia-tolerant species, blood and tissue oxygen concentrations drop to 0 or near 0 , and given the steep oxygen gradient from the vasculature to mitochondria within cells, cytochrome oxidase function must be compromised. In this situation, the inability to maintain an electrochemical gradient would result in changes in cytosolic calcium concentrations $\left(\left[\mathrm{Ca}^{2+}\right]_{\mathrm{c}}\right), \mathrm{pH}$, and perhaps in ROS levels, all of which are potential signals. Furthermore, a role in sensing low oxygen concentrations is consistent with the notion of multiple $\mathrm{O}_{2}$ sensors, each of which is sensitive to a particular range of oxygen tensions, as proposed by Prabhakar (2006).

A putative mitochondrial $\mathrm{O}_{2}$-sensing mechanism has been linked to a mitochondrial $\mathrm{K}^{+}$channel with similarities to the plasmalemmal ATP-sensitive $\mathrm{K}^{+}$channel $\left(\mathrm{mK}_{\text {ATP }}\right.$ channel; Gross and Fryer 1999; Ardehali and O'Rourke 2005; Hanley and Daut 2005). These channels are located on the inner mitochondrial membrane (Inoue et al. 1991), and their activation results in an increase in the inward $\mathrm{K}^{+}$conductance. This in turn results in an uncoupling of oxidative phosphorylation because $\mathrm{K}^{+}$ions are pumped out of the mitochondrial matrix by an $\mathrm{H}^{+} / \mathrm{K}^{+}$ exchanger. Uncoupling can ultimately lead to release of matrix $\mathrm{Ca}^{2+}$ and an increase in ROS production, both of which have been linked to $\mathrm{O}_{2}$ sensing through second messenger-mediated cascades. The structure of the $\mathrm{mK}_{\mathrm{ATP}}$ channel is unknown but thought to be structurally similar to plasmalemmal $\mathrm{K}_{\mathrm{ATP}}$ channels, which are composed of four pore-forming, inwardrectifying $\mathrm{K}^{+}$channel subunits $\left(\mathrm{K}_{\mathrm{IR}} 6.1,6.2\right)$ and four modulatory sulfonylurea receptors (SUR-1,2). Physiologically, these channels are agonized by GTP and GDP and inhibited by ATP, ADP, and long-chain coenzyme A esters. Additionally, several cellular messengers have been shown to modulate the $\mathrm{mK}_{\mathrm{ATP}}$ channel, including protein kinase $\mathrm{C}$, adenosine (ADO), and superoxide anions (Busija et al. 2005).

ATP-sensitive $\mathrm{K}^{+}$channels have been implicated as an integral component of mammalian ischemic preconditioning (IPC), and there are reports that support the opening of these channels as being a primary mediator of IPC protection in a variety of organisms and tissues. (For a review of the role of $\mathrm{mK}_{\mathrm{ATP}}$ channels in IPC, see Oldenburg et al. 2003.) The gene for this channel has not been found, and there is skepticism as to whether a discrete channel exists or whether it is a complex with other proteins, such as succinate dehydrogenase (Hanley and Daut 2005). The specificity of the common pharmacological agents, diazoxide and 5-hydroxydecanoic acid, have also been questioned; however, the evidence does indicate that an increased $\mathrm{K}^{+}$conductance is involved in IPC. This evidence is supported by studies of mitochondrial $\mathrm{BK}_{\mathrm{Ca}}$ channels that include a candidate gene and demonstrate increased $\mathrm{K}^{+}$conductance with IPC.

Given the number of potential agonists of $\mathrm{mK}_{\mathrm{ATP}}$ channels, extremely low oxygen levels may not be required for mitochondria to function as $\mathrm{O}_{2}$ sensors as mentioned above. Nevertheless, sensitivity to low oxygen and protection from anoxia-mediated cellular injury has been associated with $\mathrm{mK}_{\mathrm{ATP}}$ channels in the anoxia-tolerant western painted turtle (Pamenter et al. 2008c). In cerebral cortical sheets from this turtle, a reduction in ionotropic glutamate receptor currents (N-methyl-D-aspartate receptors [NMDAR] and $\alpha$-amino-3-hydroxy-5-methylisoxazole4-propionic acid receptors [AMPAR]) is associated with anoxia tolerance (Pamenter et al. 2008b, 2008c). Thus far, only the role of $\mathrm{mK}_{\text {ATP }}$ channels in regulating the anoxia-sensitive decrease in NMDAR currents has been investigated. In these experiments, a normoxic to anoxic transition resulted in an $10 \%$ increase in $\left[\mathrm{Ca}^{2+}\right]_{\mathrm{c}}$ and a $50 \%$ decrease in NMDAR currents. These changes were abolished by the $\mathrm{mK}_{\mathrm{ATP}}$ blocker 5-hydroxydecanoic acid (5HD), $\left[\mathrm{Ca}^{2+}\right]_{c}$ chelation with 1,2-bis(o-aminophenoxy)ethane$\mathrm{N}, \mathrm{N}, \mathrm{N}, \mathrm{N}^{\prime}$-tetraacetic acid (BAPTA) or by activation of the mitochondrial $\mathrm{Ca}^{2+}$ uniporter with spermine. Under normoxic conditions, diazoxide, the $\mathrm{mK}_{\mathrm{ATP}}$ opener, increased $\left[\mathrm{Ca}^{2+}\right]_{\mathrm{C}}$ by $10 \%$ while decreasing normoxic whole-cell NMDAR currents by $45 \%$. These changes could be blocked by 5HD, BAPTA, or spermine. Because agonists of the $\mathrm{BK}_{\mathrm{Ca}}$ channel (NS1619 and paxillin) cause similar effects, mitochondrial uncoupling via increased $\mathrm{K}^{+}$conductance and release of matrix $\mathrm{Ca}^{2+}$ may be considered a potential $\mathrm{O}_{2}$-sensing mechanism in an anoxia-tolerant organism (Pamenter et al. 2008b, 2008c).

Mitochondria are the organelles in which aerobic ATP generation occurs. Under conditions of severe hypoxia or anoxia, maintenance of mitochondrial integrity is of key importance to avoid irreversible tissue damage. A switch from anaerobic to anaerobic ATP production results in substantial reduction in efficiency of glucose metabolism and thereby a reduction in ATP generation. The corresponding decrease in ATP demand is required to avoid terminal ATP deprivation in such metabolically active tissues as the heart and the brain.

\section{Acute Metabolic Depression in Anoxia-Tolerant Brain}

Inability to match ATP production and consumption, as well as the rapid loss of the transmembrane ion gradients, is a cause of irreversible brain damage in anoxia-intolerant species, and it occurs within minutes of anoxic exposure (Nilsson 2001). Coordinated $\mathrm{O}_{2}$-sensitive regulation of the excitatory and inhibitory ligand-gated ion channels or receptors in the brain is a key to surviving acute anoxic episodes. Ion currents through these ligand-gated receptors activated by the presynaptic release 
of various neurotransmitter ligands represent a significant portion of the ion fluxes in the brain. Downregulation of excitatory ligand-gated channels that allow the entrance of $\mathrm{Na}^{+}$and $\mathrm{Ca}^{2+}$ into neurons would provide reduced neural activity and therefore reduced ATP use. The best-studied ligand-gated channel is the NMDA receptor in the anoxia-tolerant turtle Chrysemys picta bellii. This is a high-flux cation channel with a high permeability to $\mathrm{Ca}^{2+}$. In the anoxic/ischemic mammalian brain or the brain of the hypoxia-sensitive fish (rainbow trout), excessive stimulation of this receptor from uncontrolled glutamate release results in a massive inflow of $\mathrm{Ca}^{2+}$ that activates an array of death processes (Hylland and Nilsson 1999; Lipton 1999). By contrast, the brains of the crucian carp and the freshwater turtle maintain normal extracellular levels of glutamate during anoxia (Nilsson and Lutz 1991; Hylland and Nilsson 1999). Moreover, in turtle brains, NMDA-receptor activity is progressively reduced during anoxia (Bickler et al. 2000), a downregulation that has been suggested to be mediated by several mechanisms, including phosphatase 1 or $2 \mathrm{~A}$ (Bickler and Donohoe 2002), ADO receptors (Buck and Bickler 1998), and, most recently, $\mathrm{K}_{\mathrm{ATP}}$ channels (Pamenter et al. 2008b). Adding ADO to turtle brain slices causes reductions in NMDA-receptor open probability and whole-cell conductance (Buck and Bickler 1995, 1998; Ghai and Buck 1999). However; more recent data have played down the role of ADO in suppressing NMDAreceptor activity during anoxia because it appears to be a redundant interaction with a common $G$ protein (Pamenter et al. 2008c). In addition to NMDA receptors, $\mathrm{Na}^{+}$currents through $\alpha$-amino-3-hydroxy-5-methylisoxazole-4-propionic acid glutamate receptor (AMPA, a major excitatory cation channel) also decrease in the anoxic turtle brain (Pamenter et al. 2008a).

In contrast to the turtle brain, neural $\mathrm{K}^{+}$or $\mathrm{Ca}^{2+}$ permeability or fluxes appear to be maintained in the anoxic crucian carp brain (Johansson and Nilsson 1995; Nilsson 2001). Brain mRNA levels in crucian carp exposed to $1 \mathrm{wk}$ of anoxia (at $12^{\circ} \mathrm{C}$ ) suggest maintained expression of voltage-gated $\mathrm{Ca}^{2+}$ channels and AMPA receptors, while voltage-gated $\mathrm{Na}^{+}$channels upregulate by $50 \%$ and some NMDA-receptor subunits decrease by $50 \%$ (Ellefsen et al. 2008). Thus, on the level of gene transcription, there is no indication of a broad reduction of excitatory neurotransmission in this fish, with the exception of reduced NMDA-receptor function. Indeed, recent whole-cell patch-clamp recordings of slices from the goldfish telencephalon indicated a $40 \%-50 \%$ reduction in NMDA-receptor activity during $40 \mathrm{~min}$ of acute anoxia at room temperature (Wilkie et al. 2008). Nevertheless, the amino acid sequence of the crucian carp NR-1 subunit (a key part of all NMDA receptors) is very similar to that of other vertebrates, suggesting that anoxia tolerance is not dependent on alterations in the molecular structure of this major excitatory receptor (Ellefsen et al. 2008). Thus, "channel arrest" is likely an important component of the mechanism that renders the anoxic turtle nearly comatose during anoxia. However, for the crucian carp and goldfish, a major reduction in ion-channel activity is probably not compatible with maintained physical and neural activity during anoxia. These fish may rely on a faster and more dynamic way of suppressing neural activity and energy consumption: changes in the release of neurotransmitters.

Little is known about the potential role $\gamma$-amino butyric acid (GABA) receptors play in anoxia tolerance, but GABA concentrations clearly increase in the neuronal tissue of anoxiatolerant organisms (Nilsson and Lutz 1991; Lutz et al. 2003; Fig. 2). GABA is the major inhibitory neurotransmitter in the vertebrate brain. There are three GABA receptor subtypes: A, $B$, and $C$; the last is restricted to retinal neurons and is not discussed here. GABA-receptor activation initiates hyperpolarizing $\mathrm{Cl}^{-}$and/or $\mathrm{K}^{+}$currents that generally prevent membrane depolarization and the initiation action potentials. This characteristic is utilized clinically, as GABA receptors are the main target for many drugs used to induce general anesthesia (Franks 2008). $\mathrm{GABA}_{\mathrm{A}}$ receptors are anion channels that are permeable primarily to $\mathrm{Cl}^{-}$ions and normally hyperpolarize or clamp resting membrane potential $\left(E_{\mathrm{m}}\right)$ near the equilibrium potential for $\mathrm{Cl}^{-}\left(E_{\mathrm{Cl}}\right.$; the $\mathrm{Cl}^{-}$gradient determines $E_{\mathrm{Cl}}$, and $E_{\mathrm{Cl}} \approx E_{\mathrm{GABA}}$, the equilibrium potential for the $\mathrm{GABA}_{\mathrm{A}}$ receptor). $\mathrm{GABA}_{\mathrm{B}}$ receptors are connected via a $G$ protein to a $\mathrm{K}^{+}$channel and oppose excitatory electrical events in a similar fashion by in-

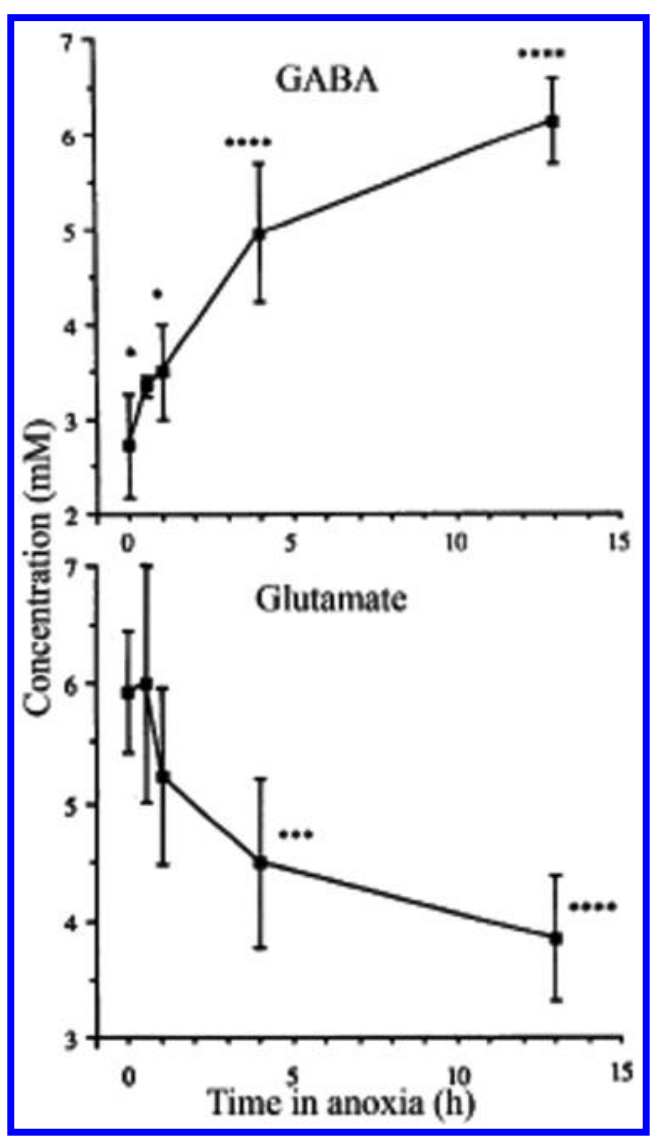

Figure 2. Reciprocal changes in brain levels of $\gamma$-amino butyric acid (GABA) and glutamate during anoxia, illustrated here in the brain of a turtle exposed to anoxia at room temperature. From Nilsson et al. (1990). 
creasing neuronal $\mathrm{K}^{+}$conductance $\left(G_{\mathrm{K}}\right)$ and hyperpolarizing or clamping $E_{\mathrm{m}}$.

Chloride is distributed unequally across the neuronal plasma membrane, extracellular concentrations being about tenfold greater than intracellular concentrations. The gradient is maintained by the balance of extrusion of $\mathrm{Cl}^{-}$though $\mathrm{K}^{+}-\mathrm{Cl}^{-}$cotransporters (KCC2), $\mathrm{Cl}^{-}$bicarbonate exchangers, ATP-driven $\mathrm{Cl}^{-}$pumps, and voltage-sensitive $\mathrm{Cl}^{-}$channels, and cellular $\mathrm{Cl}^{-}$ accumulation occurs through NKCC1 $\left(\mathrm{Na}^{+} / \mathrm{K}^{+} / 2 \mathrm{Cl}^{-}\right)$transporters (Kaila 1994; Delpire 2000). It is primarily the difference in expression of the opposing KCC2 and NKCC1 transporters that determines the neuronal $\mathrm{Cl}^{-}$gradient. Higher expression of $\mathrm{KCC} 2$ results in a $\mathrm{Cl}^{-}$reversal potential that is more negative than resting membrane potential, and an increase in $G_{\mathrm{Cl}}$ results in an inward $\mathrm{Cl}^{-}$flux and membrane hyperpolarization. Therefore, $\mathrm{GABA}_{\mathrm{A}}$-receptor activation is inhibitory. Conversely, if NKCC1 expression is higher, the $\mathrm{Cl}^{-}$potential is reduced or even reversed, and increases in $G_{\mathrm{Cl}}$ are depolarizing. Thus, $\mathrm{GABA}_{\mathrm{A}}$-receptor activation becomes excitatory.

In the central nervous system of adult mammals, the combination of expression of these transporters is such that the $\mathrm{Cl}^{-}$potential is generally negative with regard to resting membrane potential, and therefore activation of $\mathrm{GABA}_{\mathrm{A}}$ hyperpolarizes the resting membrane potential and depresses cellular excitation. The converse is true in neonates, where the $\mathrm{Cl}^{-}$gradient is reversed because of differential expression levels of the transporters, and $\mathrm{GABA}_{\mathrm{A}}$ activation is excitatory (Fiumelli and Woodin 2007) Interestingly, $\mathrm{GABA}_{\mathrm{A}}$ receptors can also function in a shuntlike fashion when $E_{\mathrm{Cl}}$ is close to $E_{\mathrm{m}}$ (Fiumelli and Woodin 2007). In this situation, an open $\mathrm{Cl}^{-}$ conductance would clamp $E_{\mathrm{m}}$ when it is close to $E_{\mathrm{Cl}}$ and counter any depolarizing conductance.

$\mathrm{GABA}_{\mathrm{A}}$ receptors may function in a shuntlike manner and play an important role in the anoxia tolerance of the western painted turtle (M. E. Pamenter and L. T. Buck, unpublished results). There are indications that $E_{\mathrm{GABA}}$ is slightly depolarized with regard to $E_{\mathrm{m}}$ in anoxic turtle neurons. Therefore, activation of the $\mathrm{GABA}_{\mathrm{A}}$ receptor during anoxia would allow $\mathrm{Cl}^{-}$ions to leave the neuron, resulting in a slight depolarization. The resulting increased $\mathrm{Cl}^{-}$conductance would oppose excitatory currents, reduce action-potential frequency, and conserve metabolic energy in the form of ATP. Another report investigating the role of the $\mathrm{GABA}_{\mathrm{A}}$ receptor in anoxia tolerance indicates that GABA is excitatory during normoxia and becomes inhibitory during severe hypoxia in pond snail neurons (Cheung et al. 2006). It was reasoned that this unusual result is based on changes in the activity of the NKCC1 transporter, because its antagonism resulted in decreased intracellular $\left[\mathrm{Cl}^{-}\right]$, thereby switching $\mathrm{GABA}_{\mathrm{A}}$-receptor activation from excitatory to inhibitory. The mechanisms underlying GABA-mediated neuroprotection from anoxia remain unclear but appear to have a certain amount of plasticity; these will be revealed by further studies of anoxia-tolerant organisms.

As mentioned above, GABA levels increase during anoxia in the brain of anoxia-tolerant vertebrates. In the turtle, the rise in extracellular GABA is massive, having reached 80 times the normoxic level within $6 \mathrm{~h}$ of anoxia (Nilsson et al. 1991). At levels that high, GABA will probably function as an endogenous anesthetic substance, mediating the near-comatose state displayed by anoxic turtles. The increase in extracellular GABA seen in the crucian carp brain is more moderate: a $50 \%$ rise after $6 \mathrm{~h}$ (Hylland and Nilsson 1999), indicating that GABA may act as a sedative rather than an anesthetic. Anesthesia has long been used to counteract brain damage caused by hypoxia and trauma in humans, and the GABA release seen in anoxic turtles and crucian carp provides an evolutionary precedent for such a treatment.

The rise in [GABA] is accompanied by an increased number of $\mathrm{GABA}_{\mathrm{A}}$ receptors in turtles (24-h anoxia at room temperature), which may function to boost the inhibitory action of GABA (Lutz and Leone-Kabler 1995). In contrast, there is a slight fall in mRNA levels of $\mathrm{GABA}_{\mathrm{A}}$-receptor subunits in crucian carp exposed to $1-7 \mathrm{~d}$ of anoxia at $8^{\circ} \mathrm{C}$, suggesting a more modest and modulated GABAergic inhibition in this species (Ellefsen et al. 2009). Nevertheless, pharmacological inhibition of GABA receptors or GABA synthesis causes a threefold increase in ethanol release to the water by anoxic crucian carp, suggesting a significant GABAergic component in anoxic whole-body metabolic depression (Nilsson 1992).

We know little of the mechanisms responsible for the anoxiainduced elevation of extracellular GABA levels seen in anoxiatolerant vertebrates. However, two contributing mechanisms have been suggested. A study has shown that the mRNA levels of transporter proteins of the GAT2 family, which is responsible for a major part of GABA reuptake, fall by $\sim 75 \%$ during anoxia (Ellefsen et al. 2009). Thus, there may be a transcriptionally induced suppression of GABA reuptake from the extracellular space during anoxia. Second, the close metabolic interrelation between GABA and glutamate will lead to a rise in tissue levels of GABA and a corresponding fall in glutamate during anoxia (Fig. 2). The reason is that GABA is synthesized directly from glutamate in an oxygen-independent reaction (catalyzed by glutamate decarboxylase), while both the synthesis of glutamate and the breakdown of GABA are oxygen dependent (Fig. 3; Siesjö 1978; Nilsson and Lutz 1993). The roles of GABA and glutamate in inhibitory and excitatory neurotransmission, respectively, are extremely well conserved in animals (from flatworms to vertebrates), and Nilsson and Lutz (1993) suggested that the selection pressure that is responsible for this functional conservation has been hypoxia. They also suggested that this particular arrangement provides a mechanism for initiating and maintaining hypoxic metabolic depression and is therefore an example of neurotransmitter metabolism functioning as an $\mathrm{O}_{2}$ sensor.

\section{Rescuing the Hypoxic Heart: Nitrite and NO in Cardioprotection}

What is beneficial for brain metabolic repression cannot be applied to the hypoxic heart. A decrease in cardiac output in response to hypoxia will compromise oxygen delivery to the hypoxic periphery. Therefore, multiple protective strategies are 


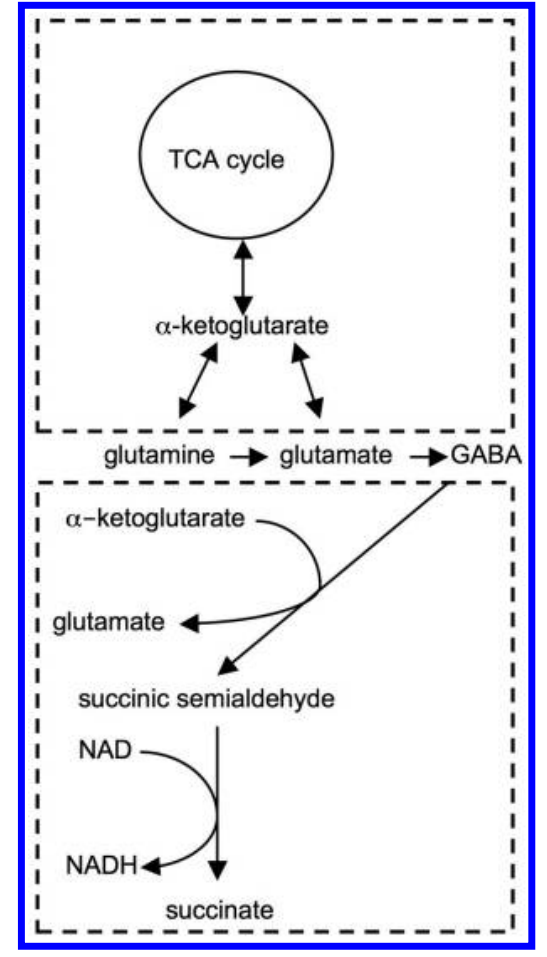

Figure 3. Interrelated metabolism of glutamate and $\gamma$-amino butyric acid (GABA) functions as an $\mathrm{O}_{2}$ sensor, causing GABA to increase and glutamate to decrease in the absence of oxygen. The reason is that both the synthesis of glutamate and the breakdown of GABA are oxygen dependent (dashed lines), while the synthesis of GABA from glutamate is oxygen independent.

utilized in this organ to optimize energy expenditure, switch to the alternative energy sources (anaerobic glycolysis), and protect the tissue from the hypoxia-induced oxidative and mechanical damage. Nitric oxide (NO) availability is a crucial element in the protection of the heart from hypoxic injury. NOSs are known as $\mathrm{O}_{2}$ sensors and are capable of generation of both antioxidative and cytoprotective NO, and superoxide anion, giving rise to prooxidative hydrogen peroxide and hydroxyl radical (Mihov et al. 2009a, 2009b). Generation of NO is an oxygen-dependent process because oxygen is a substrate of NOSs along with L-arginine. At the saturating concentrations of all substrates and cofactors, oxygen dissociation constants for different NOS isoforms range between $7.8 \mathrm{kPa}$ for the neuronal isoform (nNOS) and $5.9 \mathrm{kPa}$ for the inducible isoform (iNOS) to $0.078 \mathrm{kPa}$ for the endothelial isoform (eNOS; Dweik 2005). These values are comparable with the $\mathrm{Po}_{2}$ of most mammalian tissues under normoxic conditions: $0.13-4 \mathrm{kPa}$ in different areas of the brain, $2 \mathrm{kPa}$ in neonatal and $6-8 \mathrm{kPa}$ in adult beating heart, $4-6 \mathrm{kPa}$ in the liver, and $3.9-1.8 \mathrm{kPa}$ in the kidney cortex (Bogdanova et al. 2006; Leong et al. 2008). This suggests that even minor reductions in oxygen availability will compromise the function of nNOS and iNOS in these tissues, even in the presence of a sufficient amount of L-arginine. Nitric oxide (NO) production by eNOS was reported to slow down progressively if $\mathrm{Po}_{2}$ drops below $1 \mathrm{kPa}$ (Abu-Soud et al. 2000). Systemic hypoxia-induced inhibition of NO production was observed in vivo by monitoring exhaled NO in rabbits exposed to environmental normobaric hypoxia (Agvald et al. 2002). Reduction in de novo NOS-derived NO production was also observed in isolated neonatal rat cardiomyocytes (Bogdanova et al. 2008) and hypoxic adult myocardium (HendgenCotta et al. 2008). The presence of myoglobin and sufficient amounts of nitrite, however, was capable of compensating for the suppression of NOS activity because of the deoxymyoglobin-catalyzed conversion of $\mathrm{NO}_{2}^{-}$to $\mathrm{NO}$ in hypoxic rat heart (Hendgen-Cotta et al. 2008). In contrast, in rainbow trout heart, de novo NO production was upregulated on deoxygenation (Agnisola 2005).

A shift in the balance between $\mathrm{NO}$ and $\mathrm{O}_{2}^{-}$production under hypoxic conditions may result in oxidative stress. Oxygen affinity of superoxide anion-generating proteins exceeds that for NO generators (e.g., $K_{\mathrm{d}}$ of $2.7 \mathrm{kPa}$ for NADPH oxidases, $0.025-$ $0.01 \mathrm{kPa}$ for heme oxygenase, and $0.004-0.04 \mathrm{kPa}$ for the mitochondrial cytochrome c oxidase; Bogdanova et al. 2006). Therefore, $\mathrm{O}_{2}^{-}$produced in hypoxic tissue is largely converted to $\mathrm{H}_{2} \mathrm{O}_{2}$ by superoxide dismutase and $\mathrm{ONOO}^{-}$generation is markedly reduced because of $\mathrm{NO}$ deficiency. This results in a paradoxic oxidative-stress response to hypoxia that is observed in rat heart but not in trout heart (Bogdanova et al. 2008).

Maintenance of high levels of NO under hypoxic conditions would prevent oxidation. Whereas de novo production of $\mathrm{NO}$ by NOSs is compromised by deoxygenation, $\mathrm{NO}_{2}^{-}$becomes a major source of $\mathrm{NO}$ production because its conversion to $\mathrm{NO}$ is mediated by deoxyhemoglobin or deoxymyoglobin as well as by xanthine oxidoreductase and mitochondrial enzymes (Jensen 2009 and references therein). This makes the plasma $\mathrm{NO}_{2}^{-}$pool essential in order to maintain NO levels specifically under hypoxic conditions. In humans, plasma nitrite levels range from 0.15 to $0.20 \mu \mathrm{M}$ and do not differ from those for other mammals (0.1-0.4 $\mu \mathrm{M}$; van Faassen et al. 2009). In rainbow trout, levels are $1.9 \pm 0.4 \mu \mathrm{M}$ under normoxic conditions and can reach $8 \mu \mathrm{M}$ during hypoxia (Bogdanova et al. 2008). Unfortunately, there are no data on the nitrite levels in plasma of other fish species. Plasma $\mathrm{NO}_{2}^{-}$levels in European flounder or eelpout do not differ from those of rabbit (Jensen 2009). Furthermore, nitrite levels in flounder plasma decrease in response to hypoxia, indicating that the $\mathrm{NO}_{2}^{-}$to $\mathrm{NO}$ conversion indeed occurs in fish (Jensen 2009).

Recently, Williams et al. (2008) reported plasma $\mathrm{NO}_{2}^{-}+$ $\mathrm{NO}_{3}^{-}(\mathrm{NOx})$ in a number of fish species. According to this screening study, rainbow trout is exceptionally efficient in $\mathrm{NO}$ production among teleost fishes because its plasma [NOx] of about $30 \mu \mathrm{M}$ exceeds the $10-15 \mu \mathrm{M}$ reported for most other teleost species (Williams et al. 2008). Plasma [NOx] varies quite substantially among fish species, ranging from 1 to $3 \mu \mathrm{M}$ in cartilaginous fish (shark, skate) to 70 to $300 \mu \mathrm{M}$ in sturgeon and gar. The reported NOx content in plasma of anoxiatolerant species such as carp $(14.4 \pm 1.7 \mu \mathrm{M})$ was lower than that in hypoxia-sensitive trout. However, NOx level per se is not a reliable indicator of the potential to liberate $\mathrm{NO}$ under hypoxic conditions because it includes $\mathrm{NO}_{2}^{-}$and $\mathrm{NO}_{3}^{-}$in an 
unknown proportion. According to our data, nitrite levels in trout plasma are $1.9 \pm 0.4 \mu \mathrm{M}$ (Bogdanova et al. 2008), making up $\sim 6 \%$ of the NOx pool, whereas in human plasma, the $\mathrm{NO}_{2}^{-}$contribution does not exceed $0.5 \%-0.6 \%$ of the total $\mathrm{NOx}$ pool.

The cytoprotective function of endogenous NO in hypoxic heart tissue is generally well accepted (for review see Pacher et al. 2007). In addition to vasodilation and improvement of oxygen supply to hypoxic tissue (van Faassen et al. 2009), NO functions as an antioxidant in hypoxic myocardium. Along with reduction in $\mathrm{H}_{2} \mathrm{O}_{2}$ and $\mathrm{OH} \cdot$ levels, $\mathrm{NO}$ protects protein thiol groups from irreversible oxidation by converting them to $\mathrm{S}$ nitrosothiols and catalyzing glutathionylation (Hess et al. 2005; Hare et al. 2008). Both above-mentioned modifications may be easily reversed spontaneously (as in the case with nitrosothiols) or in reactions catalyzed by glutathione reductase on restoration of redox balance (Hidalgo 2005). This modification is involved in the regulation of ryanodine receptors and the activity of SERCA (sarco/endoplasmic reticulum $\mathrm{Ca}^{2+}$-ATPase) pumps in the heart (Bencsik et al. 2008; Lim et al. 2008). Furthermore, S-nitrosylation causes an inhibition of mitochondrial complex I, thus suppressing electron leakage in the absence of the terminal acceptor oxygen (van Faassen et al. 2009). Stabilization of myocardium mitochondria is an additional cardioprotective function of NO (Oddis and Finkel 1995; Schulz et al. 2004; Heusch et al. 2008).

Data we have obtained for changes in redox state in the myocardium (measured as a half-cell redox potential for the reduced-oxidized glutathione couple) reveal that hypoxia causes oxidative stress in rat but not trout hearts (Bogdanova et al. 2008). Hypoxic exposure caused reductions in NO production in rat cardiomyocytes (Bogdanova et al. 2008), whereas in trout heart, deoxygenation was reported to cause an upregulation in $\mathrm{NO}$ generation, thereby protecting the heart from excessive $\mathrm{H}_{2} \mathrm{O}_{2}$ generation (Agnisola 2005). As nNOS function in the myocardium is suppressed as a result of deoxygenation, nitrite is obviously serving as an additional source of NO pro duction in trout heart.

We have shown that the function of $\mathrm{Na}^{+} / \mathrm{K}^{+}$-ATPase in rodent brain (Petrushanko et al. 2006, 2007) and heart (Bogdanova et al. 2008; S. S. Yakushev and A. Yu. Bogdanova, un $\rightarrow$ published observations) is particularly sensitive to changes in redox state in the extracellular and cytosolic microenvironments and on NO production levels. Optimal function of $\mathrm{Na}^{+} \rightarrow$ $\mathrm{K}^{+}$-ATPase is possible only in the presence of endogenously produced NO; hypoxic inhibition is triggered by suppression of NOSs and reduction in NO availability (Petrushanko et al. 2007; S. S. Yakushev and A. Yu. Bogdanova, unpublished data) $\rightarrow$ Molecular mechanisms of hypoxia/NO-induced regulation of $\mathrm{Na}^{+} / \mathrm{K}^{+}$-ATPase activity include changes in phosphorylation, nitrosylation, and glutathionylation (Bogdanov et al. 2008; Fig $\rightarrow$ tree et al. 2009; S. S. Yakushev and A. Yu. Bogdanova, unpublished observations). In line with these findings, hypoxia causes a substantial reduction in the activity of $\mathrm{Na}^{+} / \mathrm{K}^{+}$-ATPase in rat but not trout ventricular tissue, in which $\mathrm{NO}$ production is upregulated on deoxygenation (Agnisola 2005; Bogdanova et al. 2008).

Taken together, interventions or adaptive strategies resulting in an increase in NO bioavailability in hypoxic heart are beneficial and protect the myocardium from hypoxic and reoxygenation-induced damage. Recent findings suggest that NO plays an important role in $\mathrm{O}_{2}$ sensing, as well as in early adaptive responses in the heart and possibly the hypoxic brain.

\section{Concluding Remarks}

Successful survival of aerobic organisms in environments where oxygen availability is variable depends on efficient $\mathrm{O}_{2}$-sensing mechanisms, including plasticity in the response to allow for rapid adjustments to changes in oxygen and preservation of homeostasis. Numerous tissue-specific $\mathrm{O}_{2}$-sensing systems with different sensory thresholds coordinate the acute adaptive responses enabling optimization of oxygen transfer and delivery to the peripheral tissues. Together they prevent irreversible ATP depletion and subsequent loss of transmembrane gradients and reduce damage from oxidative stress due to the uncoupling of processes involving electron transfer. Failure in $\mathrm{O}_{2}$ sensing or inability to respond to deoxygenation is usually fatal. This overview reveals that much is not known about the mechanisms of acute $\mathrm{O}_{2}$-sensing mechanisms. A better understanding of the adaptive mechanisms and their limitations is of great importance in analyzing the evolutionary basis of sensory mechanisms and in the assessment of hypoxic responses of individual species and those of ecosystems affected by climate change. The investigation of adaptive responses of animals (including humans) triggered by hypoxia would also provide us with powerful clinical tools to reduce mortality and morbidity in patients experiencing stroke, Parkinson and Alzheimer diseases, and cardiovascular disorders.

\section{Literature Cited}

Abu-Soud H.M., K. Ichimori, A. Presta, and D.J. Stuehr. 2000. Electron transfer, oxygen binding, and nitric oxide feedback inhibition in endothelial nitric-oxide synthase. J Biol Chem 275:17349-17357.

Agnisola C. 2005. Role of nitric oxide in the control of coronary resistance in teleosts. Comp Biochem Physiol A 142:178187.

Agvald P., L.C. Adding, A. Artlich, M.G. Persson, and L.E. Gustafsson. 2002. Mechanisms of nitric oxide generation from nitroglycerin and endogenous sources during hypoxia in vivo. Br J Pharmacol 135:373-382.

Ardehali H. and B. O'Rourke. 2005. Mitochondrial K(ATP) channels in cell survival and death. J Mol Cell Cardiol 39: 7-16.

Bencsik P., K. Kupai, Z. Giricz, A. Gorbe, I. Huliak, S. Furst, L. Dux, T. Csont, G. Jancso, and P. Ferdinandy. 2008. Cardiac capsaicin-sensitive sensory nerves regulate myocardial relaxation via S-nitrosylation of SERCA: role of peroxynitrite. $\mathrm{Br}$ J Pharmacol 153:488-496. 
Bickler P.E. and P.H. Donohoe. 2002. Adaptive responses o $\rightarrow$ Ellefsen S., G.K. Sandvik, H.K. Larsen, K.O. Stenslokken, D.A. vertebrate neurons to hypoxia. J Exp Biol 205:3579-3586.

Bickler P.E., P.H. Donohoe, and L.T. Buck. 2000. Hypoxiainduced silencing of NMDA receptors in turtle neurons. J Neurosci 20:3522-3528.

Bogdanov N., I. Petrushanko, A. Boldyrev, M. Gassmann, and A. Bogdanova. 2008. Oxygen-sensitivity of potassium fluxes across plasma membrane of cerebellar granule cells. Biochemistry 2:26-32.

Hov, T.A. Kristensen, and G.E. Nilsson. 2008. Expression of genes involved in excitatory neurotransmission in anoxic crucian carp (Carassius carassius) brain. Physiol Genomics 35:5-17.

Ellefsen S., K.O. Stenslokken, C.E. Fagernes, T.A. Kristensen, and G.E. Nilsson. 2009. Expression of genes involved in GABAergic neurotransmission in anoxic crucian carp brain (Carassius carassius). Physiol Genomics 36:61-68.

$\rightarrow$ Bogdanova A., I. Petrushanko, A. Boldyrev, and M. Gassmann $\rightarrow$ 2006. Oxygen- and redox-induced regulation of the $\mathrm{Na} / \mathrm{K}$ ATPase. Curr Enzyme Inhibition 2:37-59.

Figtree G.A., C.C. Liu, S. Bibert, E.J. Hamilton, A. Garcia, C.N. White, K.K. Chia, F. Cornelius, K. Geering, and H.H. Rasmussen. 2009. Reversible oxidative modification: a key mechanism of $\mathrm{Na}^{+}-\mathrm{K}^{+}$pump regulation. Circ Res 105:185-193.

Bogdanova A., J. Vogel, S. Yakushev, M. Segato, A. Makhro, N. Bogdanov, and M. Gassmann. 2008. Hypoxic heart: be $\rightarrow$ trout, not a rat. Pp. 225-234 in S. Morris and A. Vosloo, eds. Proceedings of the 4th CPB Meeting in Africa: Molecules to Migration: The Pressures of Life, Maasai Mara Game Re $\rightarrow$ serve, Kenya, July 19-25, 2008. Medimond International Proceedings, Bologna.

Buck L.T. and P.E. Bickler. 1995. Role of adenosine in NMDA receptor modulation in the cerebral cortex of an anoxiatolerant turtle (Chrysemys picta belli). J Exp Biol 198:16211628.

- 1998. Adenosine and anoxia reduce N-methyl-Daspartate receptor open probability in turtle cerebrocortex. J Exp Biol 201:289-297.

Fiumelli H. and M.A. Woodin. 2007. Role of activity-dependent regulation of neuronal chloride homeostasis in development. Curr Opin Neurobiol 17:81-86.

Franks N.P. 2008. General anaesthesia: from molecular targets to neuronal pathways of sleep and arousal. Nat Rev Neurosci 9:370-386.

Ghai H.S. and L.T. Buck. 1999. Acute reduction in whole cell conductance in anoxic turtle brain. Am J Physiol 277:R887R893.

Gross G.J. and R.M. Fryer. 1999. Sarcolemmal versus mitochondrial ATP-sensitive $\mathrm{K}^{+}$channels and myocardial preconditioning. Circ Res 84:973-979.

$\rightarrow$ Burleson M.L., S.E. Mercer, and M.A. Wilk-Blaszczak. 2006. Isolation and characterization of putative $\mathrm{O}_{2}$ chemoreceptor cells from the gills of channel catfish (Ictalurus punctatus). Brain Res 1092:100-107.

$\rightarrow$ Hanley P.J. and J. Daut. 2005. K(ATP) channels and preconditioning: a re-examination of the role of mitochondrial $\mathrm{K}$ (ATP) channels and an overview of alternative mechanisms. J Mol Cell Cardiol 39:17-50.

$\rightarrow$ Hare J.M., F. Beigi, and K. Tziomalos. 2008. Nitric oxide and cardiobiology-methods for intact hearts and isolated myocytes. Methods Enzymol 441:369-392.

Busija D.W., P. Katakam, N.C. Rajapakse, B. Kis, G. Grover, F. Domoki, and F. Bari. 2005. Effects of ATP-sensitive potassium channel activators diazoxide and BMS-191095 or $\rightarrow$ membrane potential and reactive oxygen species production in isolated piglet mitochondria. Brain Res Bull 66:85-90.

$\rightarrow$ Buttigieg J., S. Brown, M. Zhang, M. Lowe, A.C. Holloway, and C.A. Nurse. 2008. Chronic nicotine in utero selectively suppresses hypoxic sensitivity in neonatal rat adrenal chromaffir cells. FASEB J 22:1317-1326.

$\rightarrow$ Cheung U., M. Moghaddasi, H.L. Hall, J.J. Smith, L.T. Buck, and M.A. Woodin. 2006. Excitatory actions of GABA mediat $\rightarrow$ severe-hypoxia-induced depression of neuronal activity in the pond snail (Lymnaea stagnalis). J Exp Biol 209:44294435.

Hendgen-Cotta U.B., M.W. Merx, S. Shiva, J. Schmitz, S. Becher, J.P. Klare, H.J. Steinhoff, et al. 2008. Nitrite reductase activity of myoglobin regulates respiration and cellular viability in myocardial ischemia-reperfusion injury. Proc Natl Acad Sci USA 105:10256-10261.

Hess D.T., A. Matsumoto, S.O. Kim, H.E. Marshall, and J.S. Stamler. 2005. Protein S-nitrosylation: purview and parameters. Nat Rev Mol Cell Biol 6:150-166.

$\rightarrow$ Heusch G., K. Boengler, and R. Schulz. 2008. Cardioprotection: nitric oxide, protein kinases, and mitochondria. Circulation 118:1915-1919.

$\rightarrow$ Hidalgo C. 2005. Cross talk between $\mathrm{Ca}^{+}$and redox signalling cascades in muscle and neurons through the combined activation of ryanodine receptors $/ \mathrm{Ca} 2^{+}$release channels. Philos Trans R Soc B 360:2237-2246. parative analysis of putative oxygen-sensing cells in the fish gill. J Exp Biol 211:1231-1242.

Dejours P. 1975. Principles of Comparative Respiratory Phys $\rightarrow$ Hylland P. and G.E. Nilsson. 1999. Extracellular levels of amino iology. Elsevier, Amsterdam.

Delpire E. 2000. Cation-chloride cotransporters in neuronal communication. News Physiol Sci 15:309-312.

$\rightarrow$ Dunel-Erb S., Y. Bailly, and P. Laurent. 1982. Neuroepithelial cells in fish gill primary lamellae. J Appl Physiol 53:13421353.

Dweik R.A. 2005. Nitric oxide, hypoxia, and superoxide: the good, the bad, and the ugly! Thorax 60:265-267. acid neurotransmitters during anoxia and forced energy deficiency in crucian carp brain. Brain Res 823:49-58.

$\rightarrow$ Inoue I., H. Nagase, K. Kishi, and T. Higuti. 1991. ATP-sensitive $\mathrm{K}^{+}$channel in the mitochondrial inner membrane. Nature 352:244-247.

$\rightarrow$ Jensen F.B. 2009. The role of nitrite in nitric oxide homeostasis: a comparative perspective. Biochim Biophys Acta 1787:841848. 
Johansson D. and G. Nilsson. 1995. Roles of energy status $\rightarrow$ KATP channels and channel arrest in fish brain $\mathrm{K}^{+}$gradient dissipation during anoxia. J Exp Biol 198:2575-2580.

$\rightarrow$ Jonz M.G., I.M. Fearon, and C.A. Nurse. 2004. Neuroepithelial oxygen chemoreceptors of the zebrafish gill. J Physiol 560: 737-752.

$\rightarrow$ Jonz M.G. and C.A. Nurse. 2006. Ontogenesis of oxygen chemoreception in aquatic vertebrates. Respir Physiol Neurobiol 154:139-152.

$\rightarrow$ Kaila K. 1994. Ionic basis of $\mathrm{GABA}_{\mathrm{A}}$ receptor channel function in the nervous system. Prog Neurobiol 42:489-537.

$\rightarrow$ Leong C.L., P.M. O'Connor, G.A. Eppel, W.P. Anderson, and R.G. Evans. 2008. Measurement of renal tissue oxygen tension: systematic differences between fluorescence optode and microelectrode recordings in anaesthetized rabbits. Nephron Physiol 108:11-17.

$\rightarrow$ Lim G., L. Venetucci, D.A. Eisner, and B. Casadei. 2008. Does nitric oxide modulate cardiac ryanodine receptor function? implications for excitation-contraction coupling. Cardiovasc Res 77:256-264.

Lipton P. 1999. Ischemic cell death in brain neurons. Physiol Rev 79:1431-1568.

$\rightarrow$ López-Barneo J., P. Ortega-Saenz, R. Pardal, A. Pascual, and J.I. Piruat. 2008. Carotid body oxygen sensing. Eur Respir J 32:1386-1398.

$\rightarrow$ López-Barneo J., R. Pardal, and P. Ortega-Saenz. 2001. Cellular mechanism of oxygen sensing. Annu Rev Physiol 63:259287.

Lutz P.L. and S.L. Leone-Kabler. 1995. Upregulation of the $\mathrm{GABA}_{\mathrm{A}} /$ benzodiazepine receptor during anoxia in the freshwater turtle brain. Am J Physiol 268:R1332-R1335.

Lutz P.L., G.E. Nilsson, and H. Prentice. 2003. The Brain without Oxygen. Kluwer, Dordrecht.

$\rightarrow$ Maxime V., G. Nonnotte, C. Peyraud, P. Williot, and J.P. Truchot. 1995. Circulatory and respiratory effects of an hypoxic stress in the Siberian sturgeon. Respir Physiol 100:203212.

$\rightarrow$ Mihov D., N. Bogdanov, B. Grenacher, M. Gassmann, G. Zund, A. Bogdanova, and R. Tavakoli. 2009a. Erythropoietin pro tects from reperfusion-induced myocardial injury by enhancing coronary endothelial nitric oxide production. Eur J Cardiothorac Surg 35:839-846.

$\rightarrow$ Mihov D., J. Vogel, M. Gassmann, and A. Bogdanova. 2009 b. Erythropoietin activates nitric oxide synthase in murine erythrocytes. Am J Physiol C 297:378-388.

$\rightarrow$ Milsom W.K. and M.L. Burleson. 2007. Peripheral arterial chemoreceptors and the evolution of the carotid body. Respir Physiol Neurobiol 157:4-11.

$\rightarrow$ Nikinmaa M. and B.B. Rees. 2005. Oxygen-dependent gen $\rightarrow$ expression in fishes. Am J Physiol 288:R1079-R1090.

Nilsson G.E. 1992. Evidence for a role of GABA in metabolic depression during anoxia in crucian carp (Carassius carassiu $\rightarrow$ L.). J Exp Biol 164:243-259.

- 2001. Surviving anoxia with the brain turned on. News Physiol Sci 16:217-221.
2007. Gill remodeling in fish: a new fashion or an ancient secret? J Exp Biol 210:2403-2409.

Nilsson G.E., A.A. Alfaro, and P.L. Lutz. 1990. Changes in turtle brain neurotransmitters and related substances during anoxia. Am J Physiol 259:R376-R384.

Nilsson G.E. and P.L. Lutz. 1991. Release of inhibitory neurotransmitters in response to anoxia in turtle brain. Am J Physiol 261:R32-R37.

$\rightarrow-$. 1993. Role of GABA in hypoxia tolerance, metabolic depression and hibernation: possible links to neurotransmitter evolution. Comp Biochem Physiol C 105:329-336.

Nilsson G.E., P.L. Lutz, and T.L. Jackson. 1991. Neurotransmitters and anoxic survival of the brain: a comparison between anoxia-tolerant and anoxia-intolerant vertebrates. Physiol Zool 64:638-652.

$\rightarrow$ Nurse C.A., J. Buttigieg, R. Thompson, M. Zhang, and E. Cutz. 2006. Oxygen sensing in neuroepithelial and adrenal chromaffin cells. Novartis Found Symp 272:106-114.

Oddis C.V. and M.S. Finkel. 1995. Cytokine-stimulated nitric oxide production inhibits mitochondrial activity in cardiac myocytes. Biochem Biophys Res Comm 213:1002-1009.

$\rightarrow$ Oldenburg O., M.V. Cohen, and J.M. Downey. 2003. Mitochondrial $\mathrm{K}(\mathrm{ATP})$ channels in preconditioning. J Mol Cell Cardiol 35:569-575.

$\rightarrow$ Pacher P., J.S. Beckman, and L. Liaudet. 2007. Nitric oxide and peroxynitrite in health and disease. Physiol Rev 87:315-424.

Pamenter M.E., D.S. Shin, and L.T. Buck. 2008a. Adenosine A1 receptor activation mediates NMDA receptor activity in a pertussis toxin-sensitive manner during normoxia but not anoxia in turtle cortical neurons. Brain Res 1213:27-34.

- 2008b. AMPA receptors undergo channel arrest in the anoxic turtle cortex. Am J Physiol 294:R606-R613.

$\rightarrow$ Pamenter M.E., D.S. Shin, M. Cooray, and L.T. Buck. 2008c. Mitochondrial ATP-sensitive $\mathrm{K}^{+}$channels regulate NMDAR activity in the cortex of the anoxic western painted turtle. J Physiol 586:1043-1058.

$\rightarrow$ Pardal R., P. Ortega-Saenz, R. Duran, and J. Lopez-Barneo. 2007. Glia-like stem cells sustain physiologic neurogenesis in the adult mammalian carotid body. Cell 131:364-377.

$\rightarrow$ Perry S.F. and K.M. Gilmour. 2002. Sensing and transfer of respiratory gases at the fish gill. J Exp Zool 293:249-263.

Petrushanko I., N. Bogdanov, E. Bulygina, B. Grenacher, T. Leinsoo, A. Boldyrev, M. Gassmann, and A. Bogdanova. 2006. Na-K-ATPase in rat cerebellar granule cells is redox sensitive. Am J Physiol 290:R916-R925.

$\rightarrow$ Petrushanko I.Y., N.B. Bogdanov, N. Lapina, A.A. Boldyrev, M. Gassmann, and A.Y. Bogdanova. 2007. Oxygen-induced regulation of $\mathrm{Na} / \mathrm{K}$ ATPase in cerebellar granule cells. J Gen Physiol 130:389-398.

Prabhakar N.R. 2006. $\mathrm{O}_{2}$ sensing at the mammalian carotid body: why multiple $\mathrm{O}_{2}$ sensors and multiple transmitters? Exp Physiol 91:17-23.

Rissanen E., H.K. Tranberg, J. Sollid, G.E. Nilsson, and M. Nikinmaa. 2006. Temperature regulates hypoxia-inducible factor-1 (HIF-1) in a poikilothermic vertebrate, crucian carp (Carassius carassius). J Exp Biol 209:994-1003. 
$\rightarrow$ Schulz R., M. Kelm, and G. Heusch. 2004. Nitric oxide ir $\rightarrow$ Thompson R.J., J. Buttigieg, M. Zhang, and C.A. Nurse. 2007. myocardial ischemia/reperfusion injury. Cardiovasc Res 61: 402-413.

Siesjö B.K. 1978. Brain Energy Metabolism. Wiley, Chichester.

Slotkin T.A. and F.J. Seidler. 1988. Adrenomedullary catechol $\rightarrow$ amine release in the fetus and newborn: secretory mechanisms and their role in stress and survival. J Dev Physiol 10: $1-16$.

A rotenone-sensitive site and $\mathrm{H}_{2} \mathrm{O}_{2}$ are key components of hypoxia-sensing in neonatal rat adrenomedullary chromaffin cells. Neuroscience 145:130-141.

$\rightarrow$ van Faassen E.E., S. Bahrami, M. Feelisch, N. Hogg, M. Kelm, D.B. Kim-Shapiro, A.V. Kozlov, et al. 2009. Nitrite as regulator of hypoxic signaling in mammalian physiology. Med Res Rev 29:683-741.

$\rightarrow$ Sollid J., P. De Angelis, K. Gundersen, and G.E. Nilsson. 2003 Hypoxia induces adaptive and reversible gross morphological changes in crucian carp gills. J Exp Biol 206:3667-3673.

$\rightarrow$ Sollid J. and G.E. Nilsson. 2006. Plasticity of respiratory structures: adaptive remodeling of fish gills induced by ambient oxygen and temperature. Respir Physiol Neurobiol 154:241251.

$\rightarrow$ Sollid J., E. Rissanen, H.K. Tranberg, T. Thorstensen, K.A. Vuori, M. Nikinmaa, and G.E. Nilsson. 2006. HIF-1 $\alpha$ and iNOS levels in crucian carp gills during hypoxia-induced transformation. J Comp Physiol B 176:359-369.

$\rightarrow$ Sollid J., R.E. Weber, and G.E. Nilsson. 2005. Temperature alters the respiratory surface area of crucian carp Carassius carassius and goldfish Carassius auratus. J Exp Biol 208:1109-1116.

$\rightarrow$ Sundin L., S. Holmgren, and S. Nilsson. 1998. The oxygen receptor of the teleost gill? Acta Zool 79:207-214.

Ward J.P. 2008. Oxygen sensors in context. Biochim Biophys Acta 1777:1-14.

$\rightarrow$ Weir E.K., J. Lopez-Barneo, K.J. Buckler, and S.L. Archer. 2005. Acute oxygen-sensing mechanisms. N Engl J Med 353:20422055.

Wilkie M.P., M.E. Pamenter, S. Alkabie, D. Carapic, D.S. Shin, and L.T. Buck. 2008. Evidence of anoxia-induced channel arrest in the brain of the goldfish (Carassius auratus). Comp Biochem Physiol C 148:355-362.

Williams D.A., M.H. Flood, D.A. Lewis, V.M. Miller, and W.J. Krause. 2008. Plasma levels of nitrite and nitrate in early and recent classes of fish. Comp Med 58:431-439.

$\rightarrow$ Zhang M., H. Zhong, C. Vollmer, and C.A. Nurse. 2000. Corelease of ATP and ACh mediates hypoxic signalling at rat carotid body chemoreceptors. J Physiol 525:143-158. 